\title{
The Relationship of Achievement Motivation to Entrepreneurial Behavior: A Meta-Analysis
}

\author{
Christopher J. Collins \\ Cornell University \\ Paul J. Hanges \\ University of Maryland \\ Edwin A. Locke \\ University of Maryland
}

Entrepreneurship is a major factor in the national economy; thus, it is important to understand the motivational characteristics spurring people to become entrepreneurs and why some are more successful than others. In this study, we conducted a meta-analysis of the relationship between achievement motivation and variables associated with entrepreneurial behavior. We found that achievement motivation was significantly correlated with both choice of an entrepreneurial career and entrepreneurial performance. Further, we found that both projective and self-report measures of achievement motivation were valid. Finally, known group studies yielded a higher validity coefficient than did individual difference studies.

Nearly all supporters of the capitalistic system would agree that the encouragement of successful innovations and entrepreneurship is beneficial for the continued health and long-term growth of a nation's economy (Schumpeter, 1961). Further, small businesses account for over $50 \%$ of private sector employment and U.S. gross domestic product (Small Business Administration Office of Advocacy, 2003). Because entrepreneurship is a dominant factor in the economy, researchers have examined a number of factors that may explain entrepreneurial activity. Though a good deal of recent research has tended to focus on the characteristics of the business and industry environment or the characteristics of the entrepreneurial opportunity itself (Kaufmann \& Dant, 1998), our understanding of entrepreneurship will not be complete unless we understand the motivation of the individuals involved (Venkataraman, 1997). Indeed, recent research suggests that motivational traits are an important factor in entrepreneurial activity and success (Baum, Locke, \& Smith, 2000; Stewart \& Roth, 2001).

Research on the motivational traits of entrepreneurs seems especially promising for helping to identify those individuals that might be best suited for identifying and exploiting entrepreneurial opportunities in the marketplace (Shane \& Venkataraman, 2000). For example, individual traits and motivations may be used by schools, career counselors, investors, government agencies, and so on to identify individuals that may be suited to undertake and succeed in entrepreneurial ventures. Despite the potential importance of 
individual characteristics, there are still many unanswered questions regarding the role that motivation and personal characteristics have on entrepreneurial activity (Shane \& Venkataraman, 2000). Therefore, in this article, we seek to better understand how one important motivating factor, need for achievement, is related to both the choice of entrepreneurship as a career and performance in entrepreneurial roles.

The concept of need for achievement (nAch) was formulated in the 1950s (McClelland, Clark, Roby, \& Atkinson 1958). McClelland and his colleagues argued that high-nAch people are more likely than low-nAch people to engage in energetic and innovative activities that require planning for the future and entail an individual's responsibility for task outcomes. McClelland (1961) argued that high-nAch people should also prefer tasks that involve skill and effort, provide clear performance feedback, and were of moderate challenge or risk. He also argued that entrepreneurial positions have more of these characteristics than other types of positions. Holland's (1985) vocation choice model suggests that individuals will be most attracted to careers that offer the environmental characteristics that match their personality. Holland (1985) also argued that performance and career satisfaction are higher when there is a good fit between work environment characteristics and personality. Therefore, as was suggested by McClelland (1961), it seems likely that individuals high in nAch should be attracted to and perform well in entrepreneurial jobs.

Although there is a considerable body of literature in the area of achievement, motivation and entrepreneurship, there are important issues that have yet to be addressed. For example, Johnson (1990) conducted a traditional review of this literature and concluded that there is evidence of a relationship between achievement motivation and entrepreneurial activity. However, a close examination of Johnson's review raises some questions about the strength of this conclusion. First, because of the narrative nature of this review, the magnitude of the relationship between achievement motivation and entrepreneurial activity is unclear. In fact, many of the studies reviewed by Johnson showed non-significant relationships between achievement motivation and entrepreneurial activity. Johnson's review also indicated that there was considerable variance in the results across studies, suggesting that there may be moderators of the achievement-motivation-entrepreneurial activity relationship. In contrast to traditional reviews, meta-analysis has the potential to address some of these issues by quantitatively combining the results of individual studies to estimate the magnitude of the relationship (Hunter \& Schmidt, 1990) and by allowing formal tests of potential moderators of these relationships.

This study has three objectives. First, we assess the degree of support for McClelland's claim by conducting a meta-analytic review of the achievement motivation and entrepreneurship research that is sensitive to level of analysis issues. Second, we identify and test several potential moderators of the relation between achievement motivation and entrepreneurial action. Third, we compare the validity of achievement motivation measures as a function of measurement methodology (e.g., projective measure vs. self-report questionnaire measures). We discuss the implications of our findings for future research and for organizations and institutions interested entrepreneurship. 


\section{Background and Hypotheses}

Much of the early work on achievement motivation was conducted at the macrolevel of analysis. McClelland (1961) hypothesized that countries with a higher mean level of nAch would show more entrepreneurial activity and economic growth than those countries with a lower mean level of nAch. He found a statistically significant relationship between a country's average level of nAch (as measured by children's stories) and the subsequent economic growth of that country. He also found evidence for the relationship between nAch and entrepreneurial activity based on historical records of earlier societies. However, McClelland's claims have not gone unchallenged (e.g., Finison, 1976; Frey, 1984; Mazur \& Rosa, 1977). Both Finison (1976) and Mazur and Rosa (1977) failed to replicate McClelland's results when they corrected for statistical errors and used $1950 \mathrm{nAch}$ data to predict economic growth through 1971, and Frey (1984) found problems with McClelland's historical tests of nAch.

Because it is very difficult to isolate one causal factor at the societal level of analysis when so many causal factors are involved (Siehl \& Martin, 1990), it would seem better to test McClelland's thesis at a more micro-level. Indeed, there are a number of studies that have been conducted that examine differences in achievement motivation between both individuals and known groups. In individual differences studies, researchers have typically measured the need for achievement of individual entrepreneurs and correlated that measure with individual performance (e.g., firm growth, successfully gaining funding). Regarding studies exploring differences in achievement motivation between groups, researchers have typically utilized the "known-group" research approach discussed in the construct validity literature. That is, researchers identified two or more preexisting groups of individuals (e.g., entrepreneurs versus managers, scientists, and professionals) and tested for mean differences on some dependent variable among these groups. For example, in terms of career choice, researchers have examined mean differences in achievement motivation to test McClelland's hypotheses. Regarding job performance, researchers have assessed achievement motivation differences between high and low performing groups of entrepreneurs. In contrast to societal level studies, individual and known group studies allow cleaner assessment of McClelland's original hypotheses.

Whereas some of these micro-level studies have shown a significant relationship between achievement motivation and entrepreneurial behavior, previous reviews of this literature have uncovered three major problems. First, these reviews consistently point to the low internal consistency and test-retest reliability of the preferred measure of nAch, the TAT (Thematic Apperception Test; i.e., both types of reliability are often less than .60; Fineman, 1977). Second, although alternative achievement motivation measures (i.e., selfreport) have been developed and tend to have high levels of internal consistency and testretest stability (Fineman, 1977; Spangler, 1992), these self-report measures agree neither with projective achievement motivation measures (Fineman, 1977; Spangler, 1992) nor with each other (Fineman, 1977). Spangler (1992) reported a meta-analytic average correlation of 0.09 between the TAT and the self-report measures. Furthermore, he found that the different achievement motivation measures correlated differently with other variables and were differentially affected by moderators. Given the aforementioned two points, we decided to include both TAT and questionnaire measures in our analysis. Third, previous reviews have combined studies using different micro-(individual and group) 
levels of analysis in their reviews. However, inappropriate conclusions can be drawn when concepts developed at one level of analysis are tested at a different level of analysis (Ostroff \& Harrison, 1999). Thus, in our analysis we separated these two levels. ${ }^{1}$

Since Spangler (1992) conducted a previous meta-analysis of achievement motivation studies, some key differences between his study and ours need to be mentioned. First, in Spangler's (1992) study, only 5 out of 115 or 4\% of the studies he used involved entrepreneurs or entrepreneurial activity. In addition, Spangler's studies included a very heterogeneous array of dependent variables, including IQ test scores, attitudes, sensation seeking, enrollment in an academic honors program, performance on a ring toss game, GPA, and industrial output. This meta-analysis was restricted to only studies involving entrepreneurs and entrepreneurial performance. When testing the predictive validity of achievement motivation, at least as conceived by McClelland (1961), it seems best to restrict validity analysis to the domain where it is asserted to be most directly applicable. For example, McClelland (1965) explicitly argued that college performance was not an appropriate domain for achievement motivation (1965). Finally, Spangler did not test the homogeneity of effect size assumption (Hedges \& Olkin, 1985). We included this test, because failure to assess this assumption can lead to the aggregation of effect sizes from multiple populations resulting in an average effect size estimate that does not generalize to any particular population (Hedges \& Olkin, 1985).

By sticking closely to the most appropriate theoretical domain, ${ }^{2}$ using different measures of achievement motivation, conducting a test of homogeneity of effects, and controlling for differences between known group and individual studies, we believe that this meta-analysis has the best chance of accurately identifying the relationship between achievement motivation and performance.

\section{Definitions of Entrepreneur}

One major criticism of research in the area of entrepreneurship is that researchers have not consistently defined and operationalized what they mean by "entrepreneurs" (Kaufmann \& Dant, 1998); thus, it is difficult to compare findings across studies. Mill (1848) provided one of the earliest definitions of entrepreneurship and suggested that risk bearingwas the major feature that separated entrepreneurs from managers. McClelland (1961) also argued that risk is an essential element faced by entrepreneurs, and he argued that the definition of entrepreneurship should center around the responsibilities of initiating and being accountable for business decisions.

McClelland (1961) argued that entrepreneurs should include both the owners of small businesses and other managers with decision-making responsibilities. Following these arguments, some researchers have included both small business founders and managers when examining the role of achievement motivation.

In contrast to Mill and McClelland, Schumpeter (1934) argued that both entrepreneurs and managers face risk and instead differ in terms of their emphasis on innovation. The key notion behind this definition of entrepreneurship is the idea of growth and creation of a new business opportunity where one did not exist previously. Researchers that follow this definition tend to identify entrepreneurs as those who have initiated or guided the process of new venture creation (Shane \& Venkataraman, 2000). Typically entrepreneurs are operationalized as founders under this later definition. 
Because entrepreneurship researchers have tended to study either a broader (both founders and managers) or narrower (founders only) set of individuals, it is unclear if need for achievement is important for all types of entrepreneurial roles. Baum et al. (2000) argued that founders and managers of small businesses may face different levels of ambiguity and, thus, require different competencies. For example, founders may need higher opportunity skills whereas individuals that assume the top role of an existing small company may need more leadership and managerial skills. Thus, we expect that there may be differences in the relationship between need for achievement and entrepreneurial activity depending on how researchers defined entrepreneurs in their study.

H1. The relationship between need for achievement and entrepreneurial activity will be moderated by the definition of entrepreneurship.

\section{Known Group Versus Individual Differences Studies}

Ostroff and Harrison (1999) have recently argued that it is critical to consider the levels of analysis of the original empirical studies when conducting meta-analyses. It is inappropriate to pool studies from multiple levels of analysis because the meta-analytically derived average correlation will not be representative of any population parameter (Ostroff \& Harrison, 1999). This is a particular problem in our review because, as previously indicated, researchers have examined the effects of achievement motivation differences between both individuals and known groups. Further, the complex nature of achievement motivation makes it important to examine potential differences between known group and individual studies. Achievement motivation has been conceived of as a complex set of values associated with entrepreneurial activity (McClelland, 1961). However, though values can affect action, they are too abstract by themselves to say what a person would do in a specific situation. For example, Eisenstadt (1963) argued that the social and organizational setting in which people exist will affect the extent to which people exhibiting high levels of achievement motivation will act in an entrepreneurial manner.

Consistent with this perspective, Holland (1985) and Schneider (1987) suggested that when individuals are free to select themselves into certain groups (e.g., jobs, occupations, careers), their attraction and willingness to remain in certain jobs and careers is a function of their personality, attitudes, and values. Further, the homogeneity among people who remain in a particular job or career tend to increase as people with different personality, attitudes, and values leave these jobs or careers (Schneider, 1987). Thus, effect sizes for analyses conducted on known groups should be enhanced because the homogenization that occurs as a result of individuals staying in their careers that fit their personality and leaving careers that are a mismatch will increases the size of the difference between groups over time (e.g., entrepreneurs vs. non-entrepreneurs). ${ }^{3}$

H2. In relation to levels of analysis, achievement motivation will have a stronger association with entrepreneurial activity in known group studies than in individual difference studies. ${ }^{4}$ 


\section{Need for Achievement and Career Choice}

Holland (1985), in his theory of vocational choice, argued that individuals are most likely to be attracted to those career roles that have work characteristics that match their personalities, needs, and values. McClelland (1961) argued that individuals high in achievement motivation are more likely to pursue occupations that allow for more control over outcomes, provide more direct and immediate feedback on performance, and offer moderate levels of risk. McClelland $(1961,1965)$ further argued that entrepreneurial environments are the most likely job environments to meet these characteristics. Because entrepreneurial occupations provide more opportunities to take advantage of the characteristics associated with high achievement motivation, individuals who are high in need for achievement will be more likely to be attracted to these roles than other types of professions (Holland, 1985). Therefore, we would expect to find a significant effect size in studies examining differences in need for achievement between entrepreneurs and individuals pursuing other types of professions.

H3. There will be a significant association between achievement motivation and choice of an entrepreneurial occupation.

To show how entrepreneurs differ from other individuals on achievement motivation scores, studies have compared entrepreneurs to a wide variety of other groups ranging from managers (e.g., Cromie \& Johns, 1983; Waddell, 1983) to the general population (e.g., Hornaday \& Aboud, 1971) to politicians (e.g., Vincente-Wiley, 1979). Brockhaus (1982) argued that a potential reason for the discrepancies in findings between studies is the diverse set of comparison groups used in entrepreneurial studies; therefore, it is possible that the type of comparison sample used may be moderating the findings in the achievement motivation- entrepreneurial activity literature.

Based on McClelland's (1961) theory of nAch, one would expect that entrepreneurs should have more characteristics in common (i.e., work settings, types of challenges, etc.) with managers than they do with the general population or other types of professions, because the settings for both business managers and entrepreneurs tend to be changing at a fairly rapid pace and are open to individual initiative. In fact, McClelland (1961) identified some managers (e.g., top level) as entrepreneurs. Therefore, it is likely that individuals high in achievement motivation might also be more attracted to management positions within a business setting than to other types of positions that do not involve management in a business setting (e.g., politics, secretaries, engineers). We, therefore, predict that

H3a. In relation to career choice, achievement motivation measures will differentiate better between entrepreneurs and non-managerial roles than between entrepreneurs and managers.

\section{Need for Achievement and Performance}

Holland (1985), in his theory of vocational choice, also suggested that the interaction of work environment and personality may affect performance in a career. Specifically, he argued that higher levels of fit between the personality and work 
environment characteristics will result in higher performance in that role. McClelland $(1961,1965)$ similarly argued that need for achievement will be related to successful performance in an entrepreneurial role. Individuals who are high in achievement motivation are more likely to engage in the instrumental activities that are necessary for success in an entrepreneurial situation than are individuals low in achievement motivation (McClelland, 1965). For example, entrepreneurs who are high in achievement motivation are more likely to overcome obstacles, utilize resources for help, compete, and improve their skills. Therefore, we would expect to find a significant effect size in studies examining differences in achievement motivation for high performance entrepreneurs versus lowperformance entrepreneurs.

H4. There will be a significant association between achievement motivation and entrepreneurial performance.

\section{Career Choice Versus Performance Studies}

Though achievement motivation may significantly predict both career choice and performance, it is not necessarily the case that the effect sizes for the two distinct outcomes would be the same. McClelland $(1965,1972)$ suggested that nAch would be more likely to predict career choice than performance in an entrepreneurial position. This argument seems logical on statistical grounds alone. If it is true that those high in achievement motivation will be more likely to choose an entrepreneurial career, then there should be a restriction in the range of achievement motivation for those in entrepreneurial jobs. Thus, achievement motivation should have less power to predict which entrepreneurs would be successful and which would not be successful. In a review of achievement motivation, Johnson (1990) found that 20 of 23 studies showed a significant relationship between achievement motivation and entry into entrepreneurial positions. However, none of the 23 studies found significant ties between achievement motivation and performance of entrepreneurs. As discussed earlier, Johnson did not use any meta-analytic technique to statistically test the combined results of these studies, and we are still not clear on whether achievement motivation is related to both career choice and performance. Thus, we predict that

H5. Achievement motivation will predict entrepreneurial choice better than entrepreneurial performance.

\section{Measures of Need for Achievement}

As we noted earlier, the achievement motivation literature suggests that there are distinct differences between the types of tests used to measure achievement motivation. In his formulation of the concept of nAch, McClelland $(1961,1972)$ contended that the underlying causes of nAch are rooted in the subconscious and were developed during early childhood. Projective tests are the only method to accurately assess nAch, because it is a subconscious trait (McClelland, 1972). According to McClelland, questionnaire methods are inappropriate for measuring nAch, because they measure an individual's conscious value 
for achievement (McClelland, 1972). Therefore, McClelland (1980) argued that the TAT will be a better predictor of entrepreneurial behavior than questionnaire measures.

Though it might be expected that the TAT would perform worse because projective tests tend to have much lower reliability than questionnaire measures, there is some support for McClelland's hypothesis. For example, Spangler (1992) found that the TAT was a better predictor of outcome criterion than were questionnaires. However, as discussed earlier, Spangler did not address the issue of achievement motivation and entrepreneurship. Thus, it is still a question whether the TAT predicts performance or distinguishes between entrepreneurs and other types of individuals (i.e., predicts career choice) better than other types of measures.

This is an especially important question to answer when considering questions regarding the validity and reliability of the TAT that we raised earlier. For example, researchers and practitioners might consider using questionnaire tests that have demonstrated higher reliability if such tests are valid predictors and the TAT is not. Similarly, researchers might consider other projective tests (besides the TAT) if those tests have shown equal validity and/or higher reliability. The Miner Sentence Completion Scale is one projective test that has been used to predict entrepreneurial performance and has shown higher reliability than the TAT (Smith \& Miner, 1984). To see if the TAT is a better predictor than the other types of measures of achievement motivation, we explored the difference in predictive power of the different measures of achievement motivation (i.e., TAT, questionnaire measures, and the Miner Sentence Completion Scale) in our metaanalysis. Based on the arguments of McClelland and prior reviews of this literature, we predict that

H6. The strength of the relationship between the TAT measure of nAch and (a) occupational choice and (b) entrepreneurial performance will be significantly higher than for other projective measures or questionnaire measures of achievement motivation.

\section{Method}

Search for Primary Data

An extensive literature search was conducted for individual level studies that involved achievement motivation and entrepreneurship. The first step in locating potential studies was to review original research studies cited in a previous meta-analysis (Spangler, 1992) and in previous review articles (Johnson, 1990; McClelland, 1980). Next, we conducted a computer search using Psychlit, ProQuest, and Dissertation Abstracts International databases. Inquiries were also made of prominent researchers in the achievement motivation area to uncover any additional studies not located through the other methods. We wrote David McClelland and the McBerCorporation to see if we had missed any studies, but they could not provide us with any additional published or unpublished studies. Finally, we used the Social Sciences Citation Index to identify articles that cited key articles on achievement motivation.

Our original search resulted in a potential set of 47 studies. Twenty-one of these studies used the TAT, six used the Miner Sentence Completion Scale, and 20 used various 
types of questionnaire-based measures. We kept only those studies that conformed to the following three criteria. First, the study had to involve findings linking entrepreneurs and achievement motivation. Second, the study needed to provide either an effect size or sufficient statistical information to calculate an effect size. Finally, the study needed to provide sufficient background information and description of the variables of interest so that the study could be coded according to one or more of the potential moderators identified earlier.

Based on these criteria a total of six studies were dropped from further analysis. Four of these studies were dropped because the authors failed to provide standard deviations with reported mean scores (i.e., failed to meet the second criterion). Two other studies were dropped when we realized that the author had reported the same findings in multiple journals. For example, Singh reported the same findings in two studies (Ray \& Singh, 1980; Singh, 1979) so we retained only one of the studies in our sample. All six of the dropped studies were from the TAT set of studies. The final set used for analysis comprised 41 studies.

\section{Coding of Studies}

Coding of studies was based on the potential moderators discussed earlier. Because the studies were all field studies and did not involve any direct manipulations, the moderators clearly fell into these very broad categories (see Table 1 for examples of coding). The first step in coding the studies was to develop a coding manual based on several potential mediating variables (discussed later). Next, the first author and three research assistants independently coded the research articles. The first author and two of the three research assistants agreed on the coding for all of the studies included in the meta-analysis. The first author and the third research assistant disagreed on coding for two studies, but these discrepancies were resolved after further discussion.

A sample of coded studies can be found in Table 1. First, we coded studies based on grouping of participants (individual or known group). Studies were coded as individual level studies when researchers examined mean differences based on individual's responses and coded as known group studies when researchers examined mean differences on some dependent variable among these groups. Second, we coded studies based on dependent variable (performance or career pattern). Studies were coded as performance when the dependent variable included some form of entrepreneurial performance and as career choice when the studied compared mean differences in achievement motivation scores between entrepreneurs and some other career (e.g., scientist, manager). Note that performance measures varied across studies from secondary source measures (e.g., sales growth, stock growth) to scaled measures of performance. Type of performance measure was not a statistically significant moderator; therefore, all studies with performance as a dependent variable were included together in tests of hypotheses. Third, we coded studies based on type of career pattern comparison (entrepreneur vs. manager, non-founder or entrepreneur vs. all other types of professions). Fourth, we coded studies based on the type of test used (TAT, MSCS-t [Miner Sentence Completion ScaleForm t], or questionnaire). Finally, we coded studies based on the definition of entrepreneurship. We coded studies as following a broad definition if they included both 
founders and non-founding managers and coded them as following a narrow definition when they included only founders.

Several studies provided tests on multiple independent groups, used more than one type of achievement motivation test, or looked at more than one outcome. These independent sets of data were treated as individual data points if they could not be meaningfully collapsed. For example, Tracy, Locke, and Renard (1997) used both the TAT and the MSCS-t to measure achievement motivation and provided effect sizes for both tests. We felt that it was legitimate to treat these data points individually to test hypotheses about potential moderators. The consequence of including the multiple coefficients from a single study is that we decrease our ability to find moderators (i.e., it is a conservative bias for the test of moderators). However, including multiple correlations from the same single study may result in a liberal bias in the significance test for the general achievement motivation-activity relationship. ${ }^{5}$ To guard against the liberal bias, we replicated our results for the overall achievement motivation-activity relationship using only one average correlation per study. The results of this analysis did not significantly differ from our analyses with multiple correlations per study in terms of effect sizes or conclusions regarding hypotheses. Therefore, we have only reported the findings from the larger sample in which we included multiple coefficients from the single studies.

When accounting for studies with multiple predictors or multiple criteria, we had 69 individual data points (observed relationships between one achievement motivation measure and one outcome variable) and a total sample size of 9,032 participants. The TAT data included 24 data points and a total sample size of 2,711 participants. The MSCS-t data were made up of 15 data points and a total sample size of 1,166 . For the questionnaire data, there was a total of 30 data points and a total sample size of 5,155 participants.

\section{Transformation of Raw Data}

The studies in our sample reported results with a wide range of statistics, including $F$ tests, $t$ tests, means and standard deviations, and chi-square statistics. The raw statistics were all converted to correlations using the formulas provided by Hunter and Schmidt (1990) and Wolf (1986). Several studies reported their findings in multiple ways. When this occurred, both sets of statistics were converted and compared as a means of testing the accuracy of our conversions. In all cases, the correlations generated were statistically the same.

\section{Analyses}

We used the random effects meta-analysis method developed by Hedges and Olkin (1985) to test our hypotheses. This method treats studies as heterogeneous instead of assuming generalizability from the start as fixed effects models of meta-analysis assume. The Hedges and Olkin method first tests the overall sample for homogeneity of variance. If the homogeneity of variance hypothesis is rejected, then the sample is believed to contain true between study differences, and a weighted least-squares regression is used to test potential moderators that are identified through theory. Differences between studies that significantly explain between study variance in a regression equation are significant moderators of the relationship in question. 


\section{Results}

The correlations for all samples and measures are shown in Table 2. The test for homogeneity of variance (Hedges \& Olkin, 1985) indicated that there was significant between study variability $(Q=22.08, p<.001)$. Thus, the results indicated that moderators are operating in the relationship between achievement motivation and overall entrepreneurial activity.

H1 predicted that the relationship between achievement motivation and entrepreneurial behavior will be moderated by the definition of entrepreneurship. As shown in Table 2, the mean correlation for studies defining entrepreneurs as founders was .21 and the mean correlation for studies defining entrepreneurs as business leaders was .19. Further, as shown in Table 3, the weighted least squares analysis did not show support for our hypothesis, $F(1,58)=.41$, ns. Therefore, it does not appear that the relationship between achievement motivation and entrepreneurial activity varies depending on how researchers have defined entrepreneurs in their study.

$\mathrm{H} 2$ predicted that achievement motivation will have a have a stronger association with entrepreneurial activity in known group studies than in individual studies. When all need for achievement studies were included (see Table 2), the respective mean correlations were .18 in individual studies and .25 in known group studies. As shown in Table 3, the weighted least squares analysis showed support for this hypothesis, $F(1,67)=$ $3.42, p<.05$. When we examined this relationship with only the performance studies, we again found a large difference in effect sizes across levels of analysis. The mean correlation between achievement motivation and performance was .46 in known group studies and .18 in individual studies. As shown in Table 3, these mean correlations were significantly different, $F(1,26)=24.60, p<.01$. Thus, $\mathrm{H} 2$ is supported; it appears that the relationship between achievement motivation and entrepreneurial activity is stronger in known group studies than in individual studies.

H3 predicted that achievement motivation would be significantly related to choice of an entrepreneurial occupation. Note that career choice has only been studied using the known group design. The analyses showed significant correlations between achievement motivation and career choice $(r=.21, p<.001)$. The lower bound of the $95 \%$ confidence interval was .18 and the upper bound was .24. Because the confidence interval did not contain zero, H3 was supported. It appears that individuals that pursue entrepreneurial careers are significantly higher in achievement motivation than individuals that pursue other types of careers.

H3a predicted that the relationship between achievement motivation and career choice will be moderated by the comparison sample that is used. Specifically, we predicted that achievement motivation will have a weaker relationship with career choice when the sample compared entrepreneurs and managers than when the sample compared entrepreneurs and non-managers. The correlation between achievement motivation and career choice was lower when the sample included only managers (mean $r=.14$ ) than when it included all other professions (mean $r=.35$ ). The regression equation showed a significant difference between the two types of studies, $F(1,39)=14.78, p<.01$. Therefore, 
it appears that the sample of participants involved in the study moderates the achievement motivation-career choice relationship.

H4 predicted that achievement motivation would be significantly related to performance. As noted before, the analyses for known group studies showed a significant mean correlation between achievement motivation and performance $(r=.46, p<.01)$ with a lower bound of .42 and an upper bound of .49. The analyses of individual studies also showed a significant correlation between achievement motivation and performance $(r=$ $.18, p<.01$ ) with a lower bound of .15 and an upper bound of .22.Becauseneither of these confidence intervals included zero,H4is supported. ${ }^{6}$

TABLE 2

Average Correlations for Different Subgroups of Studies

\begin{tabular}{|c|c|c|c|}
\hline Analysis & No. of Studies & $N$ & $\begin{array}{c}\text { Hedges and } \\
\text { Olkin } M r\end{array}$ \\
\hline \multicolumn{4}{|c|}{ Hypothesis 1: Definition of entrepreneurs } \\
\hline Entrepreneurs as founders & 33 & 4,453 & .21 \\
\hline Entrepreneurs as business leaders & 27 & 2,989 & .19 \\
\hline \multicolumn{4}{|l|}{ Hypothesis: Levels of analysis } \\
\hline Individual differences studies & 20 & 2,181 & .18 \\
\hline Known group studies & 49 & 6,851 & .25 \\
\hline Hypothesis 3: Career Choice & 41 & 5,814 & .21 \\
\hline Entrepreneurs vs. managers & 21 & 3,823 & .14 \\
\hline Entrepreneurs vs. all others & 20 & 1,991 & .35 \\
\hline \multicolumn{4}{|l|}{ Hypothesis 4: Performance correlation } \\
\hline Individual level & 20 & 2,181 & .18 \\
\hline Group level & 8 & 1,037 & .46 \\
\hline \multicolumn{4}{|l|}{ Hypothesis 6} \\
\hline \multicolumn{4}{|l|}{ Performance studies (individual) } \\
\hline TAT & 8 & 915 & .16 \\
\hline $\operatorname{MSCS}-\mathrm{t}$ & 7 & 463 & .20 \\
\hline Questionnaire & 5 & 803 & .19 \\
\hline \multicolumn{4}{|l|}{ Career choice (known group) } \\
\hline TAT & 10 & 907 & .20 \\
\hline $\operatorname{MSCS}-\mathrm{t}$ & 6 & 555 & .23 \\
\hline Questionnaire & 26 & 4,424 & .20 \\
\hline
\end{tabular}


TABLE 3

Moderator Analysis

\begin{tabular}{llcc}
\hline Hypothesis & \multicolumn{1}{c}{ Analysis } & No. of Studies & F value \\
\hline Hypothesis 1 & Definition of entrepreneur & 60 & .41 \\
Hypothesis 2 & Levels of analysis & 69 & $3.42^{*}$ \\
& Levels of analysis within performance studies & 28 & $24.60^{* *}$ \\
Hypothesis 3a & Career choice (group level) & 41 & $14.78^{* *}$ \\
& $\quad \begin{array}{l}\text { entrepreneurs and managers vs. entrepreneurs } \\
\text { and other professions }\end{array}$ & & \\
Hypothesis 5 & $\begin{array}{l}\text { Performance studies vs. career choice studies at } \\
\text { group level of analysis }\end{array}$ & 49 & $15.58^{* *}$ \\
Hypothesis6 & Measurement type: TAT vs. MSCS-t vs. & & \\
& $\quad$ questionnaire \\
& $\quad$ Within performance studies (individual) & 20 & .47 \\
& $\quad$ Within career choice studies (known group) & 41 & .58 \\
\hline
\end{tabular}

${ }^{*} p<.05 .{ }^{* *} p<.01$.

H5 predicted that achievement motivation would predict entrepreneurial choice better than entrepreneurial performance. The results with known group studies showed that the respective mean correlations were .21 (choice) and .46 (performance). Further, the regression results showed a significant difference between the relationships of achievement motivation and the two outcome variables, $F(1,47)=15.58, p<.01$. Therefore, there does appear to be a significant difference in the strengths of the relationships between need for achievement and the two different types of dependent variable; however, the difference was in the direction opposite of what we predicted. In known group studies, it appears that achievement motivation is better able to explain performance differences than career choice differences. This hypothesis could not be tested for individual difference studies, because, as indicated earlier, we found no career choice studies conducted with this method.

H6 predicted that the type of achievement motivation measure would moderate the correlation of achievement motivation with the outcome criterion. Specifically, we predicted that the strength of the relationship between the TAT measure of achievement motivation and entrepreneurial activity would be significantly higher than it is for either other projective measures or questionnaire measures of achievement motivation. The analyses showed mean correlations of .16 (TAT), .19 (questionnaire), and .20 (MSCS-t) for the performance studies at the individual level of analysis and mean correlations of 20 (TAT), .20 (questionnaire), and .23 (MSCS-t) for career choice studies at the group level of analysis. As shown in Table 3, there were no significant differences in the mean correlations between the measurement types-performance studies, $F(2,17)=.47, n s$; career choice studies, $F(2,38)=.58$, $n s$. Thus, it appears as though there is no difference in the relationship between achievement motivation and entrepreneurial activity across the different measures of achievement motivation. ${ }^{7}$ 


\section{Discussion}

Overall, our results support McClelland's theory that achievement motivation is significantly related to both occupational choice and performance in an entrepreneurial role. Although these results superficially agree with prior reviews (e.g., Spangler, 1992) in showing that need for achievement is related to action, our results were based on entrepreneurship studies-the domain that is directly relevant to achievement motivation. Further, we found a stronger relationship between need for achievement and entrepreneurial activity in known group studies (mean $r=.25$ ) than in individual level studies (mean $r=.19$ ). Consistent with Holland and Schneider, achievement motivation appears to be an important characteristic for entrepreneurs; thus, the correlations from known group studies were stronger because of the increasing similarity among these entrepreneurs over time.

We were surprised that we failed to find support for McClelland's hypothesis that achievement motivation strength would predict career choice better than it predicted performance. For the known group studies, we found the exact opposite to hold. The mean $r$ for performance was significantly higher than the mean $r$ for career choice (.46 vs. .21). Although both correlations were significant, this finding suggests that achievement motivation may be particularly potent at differentiating between successful and unsuccessful groups of entrepreneurs. Thus, achievement motivation may be particularly useful for selecting entrepreneurs that may be more likely to successfully take advantage of entrepreneurial financing and other supporting activities. However, we note that the mean $r$ for career choice may be lower than that for performance because individuals high in achievement motivation may be attracted to several different types of careers. For example, our results suggested that managers are much more similar to entrepreneurs in terms of their achievement motivation than are individuals attracted to other, less similar careers such as engineers or scientists. Thus, achievement motivation may be a useful predictor of career choice for a number of types of positions that have job characteristics and responsibilities similar to entrepreneurial positions.

Also contrary to McClelland's arguments, we found that the TAT showed no greater validity than other projective tests or than self-report questionnaire measures in predicting performance or career choice. When we examined the results for performance at the individual level, the mean correlation for the TAT studies is .16compared to .20 for MSCS- $t$ studies and .20 for the questionnaire studies. For predicting career choice at the group level, the mean correlations are again very similar (.21 for the TAT, .23 for the MSCS-t, and .22 for the questionnaire). Our failure to find a higher mean validity $r$ for the TAT contradicts the findings of Spangler's (1992) meta-analysis and those of more traditional reviews (e.g., Johnson, 1990). In a review of the raw data, it appears that recent studies using the TAT have reported much lower correlations with entrepreneurial activity than did the earlier studies conducted by McClelland. Thus, it is possible that the mean $r$ for TAT studies may have been affected by undertraining on the intricacies of evaluating the TAT or other errors that may have led to incorrect scoring by later researchers who did not have the same level of experience with the test as McClelland. We were unable to test this post hoc speculation because we could not find data to test for reliability differences between McClelland and other researchers. However, if our speculation is true, it suggests that 
practitioners should rely on questionnaire measures of achievement motivation that are easier to administer and accurately score.

A second practical implication based on our findings is that practitioners may consider using both self-report and projective measures to assess achievement motivation, because previous studies have shown consistently that TAT, MSCS-t, and questionnaire measures of achievement motivation are valid but not significantly correlated or correlated at a very low level (e.g., Fineman, 1977). These low correlations suggest that the different measures of achievement motivation must be measuring different aspects of achievement motivation. As noted, McClelland has argued that TAT measures get at subconscious motives whereas questionnaires get at conscious motives. The question arises, then, whether using multiple types of measures will yield greater total validity than using only one alone. Future studies should test this hypothesis.

Our results were consistent with McClelland's prediction that individuals high in achievement motivation are more likely to be attracted to occupations that offer high degrees of control over outcomes, personal responsibility, feedback on performance, and moderate degree of risk. As predicted, we found a significant overall effect size in studies comparing achievement motivation of individuals that pursued entrepreneurial versus other types of careers. However, just as Brockhaus (1982) argued, we found greater differences in achievement motivation between entrepreneurs and people in all other professions than between entrepreneurs and managers. As we indicated previously, this result is not surprising because managers' jobs often have some entrepreneurial elements, and entrepreneurial jobs typically entail management activities. Organizations in highpaced environments that are looking for people to take on entrepreneurial roles (i.e., those that involve personal responsibility, feedback on performance, and a moderate degree of risk) to help drive innovations within the firm may wish to use achievement motivation as one of several selection criteria.

Although one might question the utility of a concept that accounts for so little variance ( $R 2$ at the group level $=.06, R 2$ at the individual level $=.04$ ), it is important to remember that the influence of achievement motivation on behavior is not a one-time influence. Rather, there are repeated opportunities for the achievement motivation of an individual to affect their decisions and behavior over the span of a lifetime. Recent simulations by Martell, Lane, and Emrich (1996) have demonstrated that interventions that appear to have small effects (e.g., effect size of $1 \%$ explained variance) can have dramatic consequences when individuals repeatedly encounter the intervention over time. Thus, even though our meta-analysis found that only $4 \%$ to $6 \%$ of the variance in entrepreneurial behavior was accounted for by achievement motivation, the implication is that achievement motivation can have substantial consequences because there are multiple opportunities for an individual to exhibit achievement oriented behavior over his or her lifetime.

Despite the merits of meta-analysis as a means of summarizing existing findings, we feel that it is important to note several limitations of our study based on the nature of the studies that composed our sample. First, there is a bias within the field of management to publish papers with significant rather than null findings. If this bias exists in the literature on achievement motivation and entrepreneurship, then our findings may potentially overstate the true relationships between need for achievement and entrepreneurial activities. We feel that this issue may be somewhat mitigated based on the nature of the 
studies in our sample. First, we included a number of unpublished doctoral dissertations that should not have been affected by this bias. Second, a large portion of our studies examined a number of predictor variables besides achievement motivation; thus, these studies were more likely to be published even if need for achievement was a nonsignificant predictor.

A second limitation is that the original studies were unlikely to have data on ventures that failed; thus, the sample of entrepreneurs was constrained to those that managed or owned surviving businesses. If need for achievement does predict entrepreneurial success, then this limitation potentially constrains the range of variability on need for achievement. In other words, this limitation in the original studies should limit our ability to find a relationship between need for achievement and entrepreneurial activity; our study may be a conservative test of this relationship. A final limitation is that the original studies were correlational rather than predictive in nature, limiting our ability to assess the direction of causation. It is possible that entrepreneurs may be socialized into becoming high nAch because of the goals, deadlines, and accomplishments that are part of the role of entrepreneurs. Indeed, the few predictive studies in the literature on need for achievement and entrepreneurship provide mixed findings. Early studies by McClelland (1965) and Durand and Shea (1974) found that scores on achievement motivation significantly predicted entrepreneurial activity years later. A later study by McClelland (1972) did not confirm this relationship. Therefore, additional research is needed to explore the direction of the relationship between the achievement motivation and entrepreneurial behavior.

In summary, we found that achievement motivation does significantly predict entrepreneurial activity (both choice of an entrepreneurial occupation and performance in that role) across the studies that were included in this meta-analysis. Further, we argued that the relatively small variance in entrepreneurial activity that was explained by achievement motivation might have significant implications because of the multiple opportunities for an individual to exhibit achievement- oriented behavior. Further, our findings suggest that achievement motivation may be particularly potent in predicting outcomes at particular levels of analysis and in specific situations. Of course, it is simplistic to think that personality alone is the key to entrepreneurship. Many other factors are involved in the success of new business venture and venture growth. Baum et al. (2000), for example, found that five different domains of variables predicted venture growth: personality traits, situationally specific motivation (goals, self-efficacy, vision), skills, business strategies, and environmental factors. Furthermore, some of these domains had direct effects, others had indirect effects, and others had both. Thus, trait factors should be viewed as only one causal factor in a complex model of factors that promote venture success. Additional research is needed to determine whether achievement motivation would still retain a significant role in such a multivariate model.

\section{References}

(References marked with an asterisk indicate studies included in the meta-analysis.)

*Ahmed, S. U. (1985). nAch, risk-taking propensity, locus of control and entrepreneurship. Personality and Individual Differences, 6, 781-782. 
*Babb, E. M., \& Babb, S. V. (1992). Psychological traits of rural entrepreneurs. The Journal of Socio-Economics, 21, 353-362.

Baum, R., Locke, E. A., \& Smith, K. G. (2000). A longitudinal model of a multi-dimensional model of venture growth. Academy of Management Journal, 44, 292-303.

*Begley, T. M. (1995). Using founder status, age of firm, and company growth rate as the basis for distinguishing entrepreneurs form managers of smaller businesses. Journal of Business Venturing, 10, 249-263.

*Begley, T. M., \& Boyd, D. P. (1987). A comparison of entrepreneurs and managers of small business firms. Journal of Management, 13, 99-108.

Brockhaus, R. H. (1982). The psychology of the entrepreneur. In C. A. Kent, D. L. Sexton, \& K. H. Vesper (Eds.), Encyclopedia of entrepreneurship (pp. 39-57). Englewood Cliffs, NJ: Prentice-Hall.

*Carland, J. W. (1982). Entrepreneurship in a small business setting: An exploratory study. Unpublished doctoral dissertation, University of Georgia.

*Cromie, S., \& Johns, S. (1983). Irish entrepreneurs: Some personal characteristics. Journal of Occupational Behaviour, 4, 317-324.

*DeCarlo, J. F., \& Lyons, P. R. (1979). A comparison of selected personal characteristics of minority and non-minority female entrepreneurs. Journal of Small Business Management, $12,22-29$.

*Dorer, L. (2001). Motivational differences between entrepreneurs and employees: A comparison of three models. Unpublished doctoral dissertation, Virginia-CommonwealthUniversity.

*Durand, D., \& Shea, D. (1974). Entrepreneurial activity as a function of achievement motivation and reinforcement control. The Journal of Psychology, 88, 57-63.

Eisenstadt, S. N. (1963). The need for achievement. Economic Development and Cultural Change, 11, 420-431.

Fineman, S. (1977). The achievement motive construct and its measurement: Where are we now? The British Journal of Psychology, 68, 1-22.

Finison, L. J. (1976). The application of McClelland's national development model to recent data. The Journal of Social Psychology, 98, 55-59.

Frey, R. S. (1984). Need for achievement, entrepreneurship, and economic growth: A critique of the McClelland thesis. The Social Science Journal, 21, 125-134. 
*Hansemark, O. C. (1999). Predictive validity of TAT and CMPS on the entrepreneurial activity, "start of a new study": A longitudinal study. Journal of Managerial Psychology, 15, 634-654.

Hedges, L. V., \& Olkin, I. (1985). Statistical methods for meta-analysis. Academic.

*Hines, G. H. (1973). Achievement motivation, occupations, and labor turnover in New Zealand. Journal of Applied Psychology, 58, 313-317.

Holland, J. L. (1985). Making vocational choices. Englewood Cliffs, NJ: Prentice Hall.

*Hornaday, J. A.,\& Aboud, J. (1971). Characteristics of successful entrepreneurs. Personnel Psychology, 24, 141-153.

*Hull, D. L., Bosley, J. J., \& Udell, G. G. (1980). Renewing the hunt for heffalump: Identifying potential entrepreneurs by personality characteristics. Journal of Small Business, 18, 11-18.

Hunter, J. E., \& Schmidt, F. L. (1990). Methods of meta-analysis. Newbury Park, CA: Sage.

Johnson, B. R. (1990). Toward a multidimensional model of entrepreneurship: the case of achievement motivation and the entrepreneur. Entrepreneurship Theory and Practice, 14, 39-54.

Judd, C. M., Smith, E. R., \& Kidder, L. H. (1991). Research methods in Social Relations (6th ed.). Orlando, FL: Harcourt Brace.

Kaufmann, P. J., \& Dant, R. P. (1998). Franchising and the domain of entrepreneurship research. Journal of Business Venturing, 14, 5-16.

*Lee, D. Y., \& Tsang, E.W. K. (2001). The effects of entrepreneurial personality, background and network activities on venture growth. Journal of Management Studies, 38, 584-602.

*Lee, J. (1997). The motivation of women entrepreneurs in Singapore. International Journal of Entrepreneurial Behavior and Research, 3, 93-110.

*Lynn, R. (1969). An achievement motivation questionnaire. British Journal of Psychology, 60, 529-534.

Martell, R. F., Lane, D. M., \& Emrich, C. (1996). Male-female differences: A computer simulation. American Psychologist, 51, 157-159.

Mazur, A., \& Rosa, E. (1977). An empirical test of McClelland's achieving society theory. Social Forces, 55, 769-774.

*McClelland, D. C. (1961). The achieving society. Princeton, NJ: Van Nostrand. 
*McClelland, D. C. (1965). Toward a theory of motive acquisition. American Psychologist, 20, 321-333.

McClelland, D. C. (1972). Opinions predict opinions: So what else is new? Journal of Consulting and Clinical Psychology, 38, 325-326.

McClelland, D. C. (1980). Motive dispositions: The merits to operant and respondent measures. In L. Wheeler (Ed.), Review of personality and social psychology (Vol. 1, pp. 1041). Beverly Hills, CA: Sage.

McClelland, D. C., Clark, R. A., Roby, T. B., \& Atkinson, J. W. (1958). The effect of the need for achievement on thematic apperception. In J.W. Atkinson (Ed.), Motives in fantasy, action and society (pp. 64-82). Princeton, NJ: Van Norstrand.

Mill, J. S. (1848). Principles of political economy with some of their applications to social philosophy. Boston: C. C. Little and Brown.

*Miner, J. B., Smith, N. R., \& Bracker, J. S. (1989). Role of entrepreneurial task motivation in the growth of technologically innovative firms. Journal of Applied Psychology, 74, 554-560.

*Miner, J. B., Smith, N. R., \& Bracker, J. S. (1994). Role of entrepreneurial task motivation in the growth of technologically innovative firms: Interpretations from follow-up data. Journal of Applied Psychology, 79, 627-630.

*Morris, J. L., \& Fargher, K. (1974). Achievement drive and creativity as correlates of success in small business. Australian Journal of Psychology, 26, 217-222.

*Nandy, A. (1973). Motives, modernity, and entrepreneurial competence. The Journal of Social Psychology, 91, 127-136.

Ostroff, C., \& Harrison, D. A. (1999). Meta-analysis, levels of analysis, and best estimates of population correlations: Cautions for interpreting meta-analytic results in organizational behavior. Journal of Applied Psychology, 84, 260-270.

*Ray, J. J., \& Singh, S. (1980). Effects of individual differences on productivity among farmers in India. The Journal of Social Psychology, 112, 11-17.

Robbins, N. E. (1986). Entrepreneurial assessment: Characteristics which differentiate entrepreneurs, intrapreneurs and managers. Unpublished doctoral dissertation, University of Minnesota.

*Rodriguez, L. T. (2000). The wind beneath their wings: The moderating effects of social support on the entrepreneur and entrepreneurial performance. Unpublished doctoral dissertation, University of Nebraska. 
Rosenthal, R. (1979). The "file drawer problem" and tolerance for null results. Psychological Bulletin, 86, 638-641.

Schneider, B. (1987). The people make the place. Personnel Psychology, 40, 437-454.

Schumpeter, J. A. (1934). The theory of economic development: An inquiry into profits, capital, credit, interest, and the business cycle. Cambridge, MA: Harvard University Press.

Schumpeter, J. A. (1961). The theory of economic development. Cambridge, MA: Harvard University Press.

Shane, S.,\&Venkataraman, S. (2000). The promise of entrepreneurship as a field of research. Academy of Management Review, 25, 217-226.

Siehl, C., \& Martin, J. (1990). Organizational culture: A key to financial performance? In B. Schneider (Ed.), Organizational climate and culture (pp. 241-281). San Francisco: JosseyBass.

*Singh, S. (1969). nAch among successful-unsuccessful and traditional progressive agricultural entrepreneurs of Delhi. Journal of Social Psychology, 79, 145-149.

*Singh, S. (1970). nAch among agricultural and business entrepreneurs of Delhi. The Journal of Social Psychology, 81, 145-149.

*Singh, S. (1979). Relationships among projective and direct verbal measures of achievement motivation. Journal of Personality Assessment, 43, 45-49.

*Singh, S., \& Ray, J. J. (1980). Modernization and development among Indian farmers: A modern proof of some old theories. Economic Development and Cultural Change, 80, 509521.

Small Business Administration Office of Advocacy. (2003). Small business share of economic growth. Office of economic research: Research publications 2002. Retrieved April 5, 2003 from http://www.sba.gov.advo

*Smith, N. R., \& Miner, J. B. (1984). Motivational considerations in the success of technologically innovative entrepreneurships. In J. A. Hornaday, E. B. Shils, J. A. Timmons, \& K. H. Vesper (Eds.), Frontiers of entrepreneurship research (pp. 482-488). Wellesley, MA: Babson College.

*Smith, N. R., \& Miner, J. B. (1985). Motivational considerations in the success of technologically innovative entrepreneurships: Extended sample findings. In J. A. Hornaday, E. B. Shils, J. A. Timmons, \& K. H. Vesper (Eds.), Frontiers of entrepreneurship research (pp. 482-488). Wellesley, MA: Babson College. 
Spangler, W. D. (1992). Validity of questionnaire and TAT measures of need for achievement: Two meta-analyses. Psychological Bulletin, 112, 140-154.

*Stewart, W. H., Watson, W. E., Carland, J. C., \& Carland, J.W. (1995). A proclivity for entrepreneurship: A comparison of entrepreneurs, small business owners, and corporate managers. Journal of Business Venturing, 14, 189-214.

Stewart, W. H., \& Roth, P. L. (2001). Risk propensity differences between entrepreneurs and managers: A meta-analysis review. Journal of Applied Psychology, 86, 145-153.

*Sutcliffe, C. R. (1974). Achievement motivation and economic development among peasants: An exploration of measurement problems. Rural Sociology, 39, 238-246.

*Tracy, K. B., Locke, E. A., \& Renard, M. K. (1997). Conscious goal setting versus subconscious motives: Longitudinal and concurrent effects on the performance of entrepreneurial firms. Unpublished paper, University of Maryland at College Park.

Venkataraman, S. (1997). The distinctive domain of entrepreneurship research: An editor's perspective. In J. Katz \& R. Brockhaus (Eds.), Advances in Entrepreneurship, firm emergence, and growth (Vol. pp. 119-138). Greenwich, CT: JAI.

*Vicente-Wiley, L. (1979). Achievement values of Filipino entrepreneurs and politicians. Economic Development and Cultural Change, 79, 467-483.

*Waddell, F. T. (1983). Factors affecting choice, satisfaction, and success in the female selfemployed. Journal of Vocational Behavior, 23, 294-304.

*Wainer, H. A., \& Rubin, I. M. (1969). Motivation of research and development entrepreneurs: Determinants of company success. Journal of Applied Psychology, 53, 178184. Wolf, F. M. (1986). Meta-analysis: Quantitative methods for research synthesis. Newbury Park, CA: Sage.

${ }^{1}$ For a further discussion of the problems of ecological fallacies, see Judd, Smith, and Kidder (1991).

2 McClelland does not consider nAch to be a predictor of performance in a traditional, bureaucratic firm; rather he uses his leadership motive pattern (which involves a certain relationship between nPower, power inhibition, and nAffiliation). 3 It should be noted that our expected enhanced effect of nAch and performance at the group level of analysis is different from McClelland's societial level hypotheses because our hypothesis depends on people freely selecting themselves into and out of groups. Clearly, society level of analyses include more people than just those who freely select themselves into that society.

${ }^{4}$ As suggested by Ostroff and Harrison (1999), we began by examining whether need for achievement studies can be examined across levels of analysis. If this hypothesis is supported, then all of the following hypotheses will be tested at both the group and individual levels of analysis where appropriate.

5 Though inclusion of multiple correlations from the same sample will not affect the average correlation estimate, it will affect the variance in correlations across studies.

6 We performed Rosenthal's (1979) file-drawer analysis and found that 86 studies would be needed to change our results. Given the extensive nature of our search to find studies focusing on entrepreneurs, these results appear to be stable.

7 We corrected our average correlations for measurement error by applying the correction for attenuation formula. Using Fineman (1977), we estimated the reliability of the TAT at .54, the reliability of questionnaire methods to be .62, and the reliability of the MSCS to be .65. After averaging the meta-analysis correlations for each measure, the results did not significantly differ. 